\title{
Pengguna Media Interaktif Sebagai Kenyataan Maya: Studi Resepsi Khalayak Suarasurabaya.net Sebagai Media Interaktif
}

\author{
Ido Prijana Hadi \\ Program Studi Ilmu Komunikasi, Universitas Kristen Petra \\ Sedang Menempuh Studi S-3 Bidang Komunikasi di Universitas Padjadjaran
}

\begin{abstract}
My aim in writing this paper is to describe that in this fast-changing world, media in Indonesia has undergone a rapid transformation. Digital technology continues to reshape the mass media landscape using internet technology. Internet brings a technical communication revolution, a fundamental change takes place in the structure of connections, artificial memories and the reproduction of their content. Internet technology has made communication much easier and less expensive. It has attracted many people and has penetrated into people's daily lives. The mass media also have accepted the internet. Almost all forms of traditional media (old media) in local media, such as radio, television, and newspaper have extended their work into this new field. The internet and the world wide web have both significantly influenced modern journalism.

In online media allows readers to enjoy browsing their product and service of contents, such as news feed, podcasts, deskstop alert, news on mobile phones, PDA and others mobile devices. Online media offer not only text but also digital images, audio file, moving images (video), internet radio and internet $t v$. The interactive features of the internet seemingly imply that online media have more advantages than traditional media forms (old media). So, the internet have dramatically evolved become new media with characteristic multimedia, hypertext, interactivity, archives, and virtuality. The most important structural new media characteristic is the integration of telecommunications, data communications and mass communication in a single medium - it is the convergence. It should be pointed out that the trend toward digital is affecting the various media and brings the local media in East Java to become a global media, where breaking news from Surabaya or anywhere in East Java is transmitted to around the world in a matter of minutes .

The research was carried out to find out how user reception on convergence media, journalism dan local media on the site of Suara Surabaya.net. And how to access subjective meanings that they have created based on their understanding on online media so far. The research is also interested in looking into user reception on information and communication technology based on its relevance with the selected theme namely discourse on global media in web site of Radio Suara Surabaya.
\end{abstract}

Keywords : subjective meaning, online media, user reception

\section{LATAR BELAKANG}

Internet sebagai media teknologi baru juga mempengaruhi transformasi jurnalisme secara fundamental (Pavlik, 200). Seperti serba berita (ubiquitous news), akses informasi global, peliputan saat itu juga (instantaneous reporting), interaktif, wujud isianeka media(multimediacontent), serta penyediaan isi yang luar biasa spesifik (extreme content customization). Periode internet memunculkan riset internet yang memfokuskan pada tiga 
pengembangan yaitu, peningkatan jumlah pengakses internet, pertumbuhan perbedaan antara isi media online dan off-line, dan perubahan hubungan yang terjadi antara media dan publiknya (Pavlik, 2004: 442). Perubahan 'alami' hubungan media dengan khalayak karena teknologi komunikasi dan media modern, sehingga terjadi pergeseran dari khalayak massa akhirnya menuju interactive media user (see Livingstone, 2003). Sehingga dalam penelitian khalayak akan lebih baik memahami perubahan media dan perubahan khalayak dalam perspektif analisis terintegrasi tentang produksi (production), teks (texts) dan khalayak (audiences) dalam konteks budaya (cultural contexts). Dewasa ini, penelitian khalayak $^{1}$ memusatkan pada konteks dari penggunaan media (media use), dan interpretasi atas isi media (media content).

Hal ini bisa merupakan refleksif seseorang atas konsekuensi perubahan sosial dan teknologi. Livingstone (2003) mengutip Alasuutari (1999 : 6) dalam pandangan konstruksionis (constructionist view) mengatakan "the audience" as a social phenomenon "out there" must be replaced by the recognition that the audience is "a discursive construct" produced by particular analytic gaze. Sehingga penting meredefinisi ulang batasan audience yang sedang berubah dalam hubungan antara organisasi media dan khalayaknya. Audience sedang bergerak ke arah perubahan dari komunitas secara lokal geografis menuju komunitas

\footnotetext{
Kata "audience" menurut Pavlik (2004: 443) lebih tepat dengan kata "users", karena apa yang terjadi dalam media online adalah orang aktif melakukan sesuatu, bisa sebagai "visitor" (pengunjung). Seperti mengirim e-mail, mengakses website, bahkan sampai melakukan transaksi untuk membeli sesuatu. Users secara aktif mencari isi media atau mempublikasikan informasi yang mereka miliki. Sedangkan dalam media cetak dan elektronik (TV dan Radio) audience lebih sebagai pembaca, pendengar atau pemirsa yang cenderung pasif.
}

yang tidak dibatasi secara teritori, politik, nasionalisme, etnis, dan batasanbatasan budaya. Orang bisa mengakses media dari manapun dan tidak ada perbedaan. Dalam hal ini, radio dalam era konvergensi media tidak hanya bergantung dengan frekuensi gelombang yang sangat terbatas pancaran siarannya. Bahkan radio bisa diakses secara mobile, dimana pun dan kapan pun pendengar berada sekalipun di luarnegeri. Teknologi komunikasi massa dengan paradigma lama one to many bergeser menjadi many to many.

Studi ini memfokuskan perhatiannya pada users media Suara Surabaya (http://www.suarasurabaya.net) dalam hubungannya dengan penerimaan mereka sebagai media online. Perubahan sosial dan konteks budaya juga membentuk karakter khalayak media ini. Alasan memilih media ini, karena sebagai radio lokal konvensional sangat unik, Suara Surabaya 100 FM telah menerapkan konsep format siaran radio $(20 \%$ musik dan $80 \%$ berita) news dan informasi yang interaktif sejak 1995 (berikut tim redaksi interaktif atau gatekeeper dengan motto news, interaktif, dan solutif) mendapat atensi luar biasa dari para pendengar Surabaya dan sekitarnya hingga sekarang. Format radio konvensional tetap dipertahankan, dengan mensinergikan teknologi komunikasi. Sejak tahun 2000 ketika era digital news (era cyberspace) dalam media konvergensi, radio Suara Surabaya mengembangkan berita online internet berupa teks berita online, radio internet, radio on demand, video on demand, bahkan sampai informasi cuaca, dan kurs mata uang. Sehingga dengan menerapkan teknologi internet $^{2}$ dan

\footnotetext{
Internet technology combined with increasing editorial sophistication, is empowering audiences to access local radio news of their own choosing,
} 
editorial yang menarik, Suara Surabaya mampu memberdayakan pendengar untuk mengakses berita lokal yang mereka pilih dari berbagai wilayah.

Radio internet, menurut Dijk (2004: 153) merupakan interactive broadcasting yang merupakan sebuah sebutan kolektif yang merujuk kepada digital audio broadcasting (DAB). Radio internet adalah website yang mendistribusikan program audiovisual yang juga ditransmisikan pada penyiaran reguler, dimana karakteristik pengguna komputer dan internet utamanya adalah bersifat individual yaitu di depan layar monitor. Internet menjadi ruang publik baru tempat di mana orang bisa mendapatkan informasi dengan cepat. Wacana isu-isu apa pun berkembang sangat cepat melalui internet. Sementara wujud diseminasi program siaran atau penyampaian pesan tidak saja bersifat broadcast (dipancarkan lewat frekuensi) tetapi juga melalui komputer danjaringan internet. Informasi diterima pendengar konvensional melalui gelombang FM 100 tetapi juga bisa didengarkan oleh pendengar yang sifatnya maya (virtual listener). Virtual listener atau user belum banyak diekplorasi keberadaannya oleh stasiun radio, tetapi realitanya ada banyak pengakses ${ }^{3}$ online radio. Ini merupakan kenyataan maya (virtual reality) - meminjam istilah Jaron Lanier (dalam Supelli, 2010: 339).

Fenomena komunikasi inilah yang menarik untuk dikaji dalam studi

the Internet has created a 'technological' localness in addition to the 'geographical' localness we have previously understood to limit community membership (see Crissel and Starkey, 1998: 23).

3 Data hasil observasi penulis dengan editor Suarasurabaya.net diperoleh data secara kuantitatif jumlah pengakses (hit counter) atau kunjungan ke website radio Suara Surabaya (www. suarasurabaya.net) dalam satu hari rata-rata kurang lebih 714,3 atau 5.000 pengakses dalam satu minggu dari 25 negara, mulai dari Indonesia, Belanda, Australia, dsb. keradioan kontemporer masa kini dan masa depan, seperti bagaimana sebenarnya individu sebagai pengguna memanfaatkan internet sebagai media interaktif untuk mengakses materi informasi sesuai kebutuhannya. Serta bagaimana makna subyektif pengakses (users) yang mereka ciptakan berdasarkan pemahaman dan pemaknaan mereka mengenai konvergensi media dan jurnalisme dalam media Suara Surabaya. net (SS.net) yang selama ini diaksesnya. Termasuk penerimaan users terhadap teknologi komunikasi dan informasi berdasarkan relevansinya dengan tema yang dipilih yaitu wacana mengenai media lokal yang berhasil mengglobal pada Radio Suara Surabaya (wwww. suarasurabaya.net).

\section{KAJIAN LITERATUR}

Beberapa konsep yang digunakan sebagai dasar pemahaman tentang keterkaitan studi dengan literatur yang dikaji, sehingga memberikan kontribusi terhadap pemahaman para pembaca tentang topik penelitian ini:

\section{Internet sebagai Medium Komunikasi}

Munculnya perdebatan yang problematik atas internet sebagai medium apakah sebagai media massa atau media komunikasi antarpersona lebih disebabkan oleh sifat internet itu sendiri, yang bisa diklasifikasikan ke dalam media massa atau media konvensional yang individual dan antarpersona. Internet bisa dikatakan sebagai sebuah hybrid (perkawinan) yang mana keduanya mampu bekerja sebagai perangkat $C D$ player dan televisi. Internet juga sebagai medium komunikasi antarpersona, contohnya e-mail. Jensen (1998:46) memisahkan berbagai macam media, 
yang kemudian disebut media "pull" dan "push". Media tradisional, seperti TV, radio, dan film, mempunyai karakteristik "push", dimana isi media diciptakan oleh medianya untuk pembaca, pendengar dan pemirsanya. Sedangkan dalam "pull" media (internet) isinya diciptakan oleh pengguna. Audience perannya lebih aktif ketika surfing on the net daripada ketika surfing saluran TV. Isi media bergeser dari seragam ke personal, dan siklus publikasi berkembang dari periodik menuju up to date.

Perkembangan teknologi membawa pengaruh pada isi media. Di mana isi berita dalam edisi online internet menurut Pavlik (1998) telah melewati tiga tahap yaitu : (a) surat kabar online hanya memindahkan ulang versi cetaknya ke online (repurpose content from their mother ship); (b) surat kabar sudah membuat isi inovatif-kreatif dalam websitenya dengan fitur interaktif seperti hyperlinks dan search engines, yang dapat memudahkan pengguna mencari materi dengan topiktopik khusus yang sesuai dengan ukuran kebutuhannya, misalnya dengan katagori berita dan informasi yang dipilihnya (the journalists create original content and augment it with such additives as hyperlinks - with which a reader can instantly access another website; interactive features such as search engines, which seek out material on specific topics; and a degree of customization - the ability to choose what categories of news and information you receive); dan (c) isi berita telah didesain secara khusus untuk media web sebagai sebuah medium komunikasi (original news content designed specifically for the Web as a new medium of communication).

Dalam kajian Computer Mediated Communication (CMC) terdapat makna baru dari teks yang tersedia pada para pencipta isi media. Tidak hanya dalam CMC setiap orang bisa menjadi pencipta isi media, tetapi kemungkinan menginterpretasitekslebihterbukakarena karakteristik dari hypertext. Di mana, users mampu mengakses teks secara virtual dan nonlinear, artinya tidak harus berurutan (linear) seperti membaca buku, urutan episode dalam program televisi/ radio. Jadi ketika users mengunjungi website, bisa saja tidak masuk pada halaman pertama, tetapi langsung mengakses halaman atau link ke website lain untuk mendapatkan lebih banyak informasi sesuai topik yang disebut dalam situs tersebut, dan kemudian bisa kembali ke website pertama. Ketika pengakses berselancar dari satu situs ke situs lain, pengakses sedang sedang menciptakan episode mereka sendiri. Pengakses mengontrol teks dan menginterpretasi teks tersebut. Sehingga dalam penulisan, hypertext mengubah definisi klasik dari teks, pengarang, dan pembaca (Nellis, 2004: 255).

\section{Konvergensi Media : Titik Awal Transisi}

Konvergensi secara harafiah dapat diartikan sebagai dua benda atau lebih bertemu atau bersatu di suatu titik; pemusatan pandangan yang amat dekat. Konvergensi media merupakan konsep di mana media massa lama dan baru berkelindan, ketika kalangan akar rumput dan perusahaan jalin menjalin, dengan keseimbangan kekuatan antara produsen media dan konsumen media yang saling berganti secara tidak terkira. (Runtiko, 2008:7). Nicholas Negroponte dari MIT Media Lab (dalam Kung, 2008: 93) memprediksikan, sejak tahun 1979 teknologi komunikasi akan membawa metamorfosis dunia penyiaran dan gambar bergerak (motion picture), industri komputer, dan industri cetak dan penerbitan yang secara bersama 
menciptakan sektor baru dan bentukbentuk baru komunikasi dengan model "3-C" konvergensi. Konvergensi media membawa akibat pada runtuhnya pola komunikasi massa tradisional yang sebelumnya ada. Terjadi kondisi demasifikasi, yaitu lenyapnya ciri utama media massa yang menyebarkan informasi secara masif, arus informasi menjadi semakin personal.

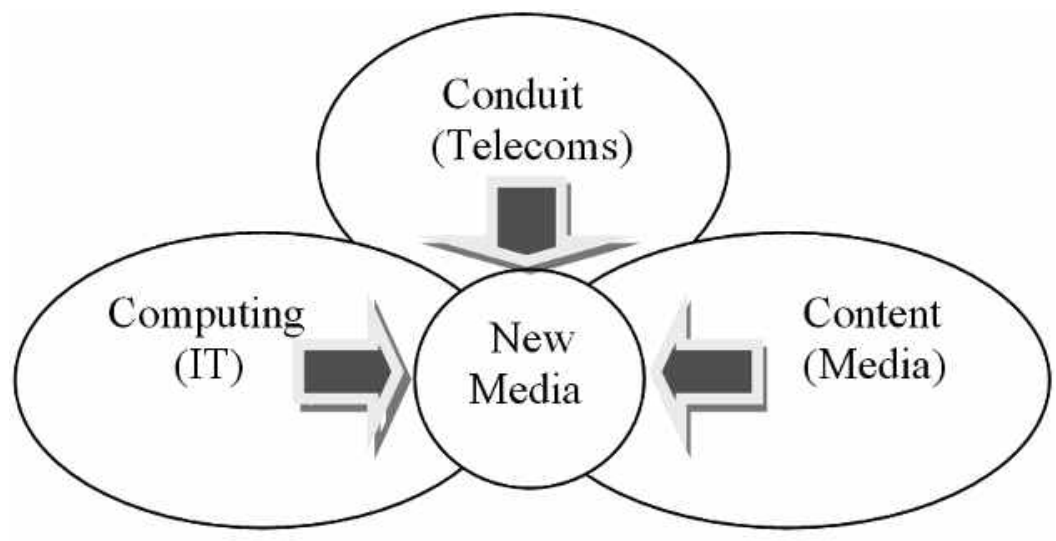

Model "3-C" Konvergensi

Sumber : Kung, 2008:93

Konvergensi media juga diartikan sebagai strategi manajemen, di mana perusahaan berusaha meningkatkan keuntungannya dengan membuat berbagai macam modal kepemilikan media. Strategi tersebut meliputi tiga elemen : 1) konsentrasi perusahaan, di mana sedikit perusahaan besar memiliki banyak bentuk media; 2) digitalisasi, dimana isi media dibuat dalam bentuk bahasa komputer, dan dapat digunakan atau diakses dalam berbagai media; 3) deregulasi pemerintah yang meningkatkan perijinan kepemilikan berbagai media pada pasaryang sama oleh konglomerat tertentu (p.7). Singkatnya, konvergensi sebagai suatu jaringan sistem informasi dan komunikasi yang lahir akibat keterpaduan perkembangan teknologi informasi dan komunikasi telah berfungsi sebagaimana layaknya suatu media komunikasi massa.

Di samping itu, informasi yang disajikan medium internet sebagai sumber informasi sama dengan medium lain, bahkan lebih unggul dari unsur kecepatan, seketika, tingkat interaktifitas, hyperlinks text sebagai sumber informasi dan tidak tergantung pada jadwal siar dan periodesitas seperti dijumpai pada surat kabar (terbit pagi atau sore). Bahkan menurutpenulismedia onlinediIndonesia yang berbasis pada lembaga yang sudah mapan, internet sudah menunjukkan kemajuan yang sangat luar biasa, tidak sekedar cetak yang dionlinekan, namun isi berita telah didesain secara khusus untuk media web sebagai sebuah medium komunikasi, seperti apa yang dikatakan Pavlik (1998). Situs berita sebagai nara sumber bukan lagi bersifat komplementer namun bersinergi dengan isi siaran, telekomunikasi (infrastruktur dan jaringan), dan komputer sehingga mampu menghadirkan jurnalisme online dengan perspektif multimedia. Sebuah 
revolusi media yang demikian maju.

\subsection{Internet dan Wacana Khalayak Global}

Sistem komunikasi internet pada prinsipnya didesain sebagai sebuah sistem narrowcasting ${ }^{4}$, yang mana di satu sisi users mengakses dan memilih informasi yang sesuai dengan kebutuhannya. Di sisi lain, internet yang awalnya mampu memberikan full service web information, akhirnya menjadi portal yang melayani informasi sesuai fokusnya (spesialisasi). Hal ini tidak lepas dari users internet yang semakin selektif dalam mengakses dan memilih informasi mana yang sesuai. Setiap individu di mana pun bisa mengakses internet untuk men-download dokumen, baik berupa teks, gambar, suara, video, dan sebagainya. Atau bahkan bisa saling berdiskusi satu sama lain dengan users lain dalam fasilitas online discussion. Sehingga, realitas maya yang menjadi karakteristik media online bagaikan perpanjangan dari sistem indra manusia yang selanjutnya menjadikan dunia terasa menyempit dan dekat.

Wacana media konvensional (radio), yang mengembangkan media online (internet) dengan cara membuka website, pada akhirnya menjadi konvergensi. Sebuah integrasi antara media konvensional, telekomunikasi, dan teknologi informasi (multimedia dan internet) yang memudahkan akses informasi bagaikan melalui jalan raya informasi bebas hambatan (information superhighway). Konvergensi media juga telah mengubah komunikasi dari yang sifatnya terbatas menjadi global. Tidak dibatasi wilayah, negara, bahkan bangsa. Sehingga, globalisasi akibat internet ini

4 Barry Cox seorang eksekutif TV menyatakan dunia penyiaran menjadi narrowcasting, dimana distribusi isi siaran ditujukan ke khalayak kecil atau niche audience (Street, John, 2001:178). memberikan kemampuan komunikasi secara instan yang bisa meruntuhkan sekat privasi. Manuel Castells (dalam Street, 2001:179) menyampaikan, "we live, not in global village, but in 'customized cottages globally produced and locally distributed".

Membicarakan media online dibandingkan dengan media konvensional analog (tradisional), dari perspektif kajian media sebenarnya terletak pada kapasitas komunikasinya. Audience online memiliki kemampuan untuk memberikan feedback kepada media secara langsung, dan relasinya bersifat interaktif. Sementara Audience media konvensional, proses komunikasi yang terjadi lebih bersifat linear, meskipun sudah banyak media yang membuka saluran interaktif untuk khalayaknya melalui mekanisme feedback. Audience online maupun media konvensional sama-sama aktif, namun audience online bisa dikatakan keaktifannya melewati apa yang ada di media konvensional. Audience online dalam proses komunikasi merupakan full participant.

Sementara interaktivitas dalam online journalism adalah adanya sebuah hubungan antara reporter dengan pembacanya (consumer) dan hubungan yang bermakna dengan sebuah bentuk baru jurnalistik. Menurut Williams, Rice, dan Rogers 1998 (dalam Severin and Tankard, 2001: 370) mendefinisikan interaktifitas sebagai "the degree to which participants in a communications process have control over, and can exchange roles in, their mutual discourse". Jadi kontrol komunikasi internet ada pada pengguna. Salah satu studi penggunaan internet mendapatkan enam dimensi interaktifitas yaitu (1) internet mampu memberikan informasi dari pada sekedar persuasi; (2) kontrol terletak pada pengguna 
internet; (3) aktifitas banyak dilakukan oleh pengguna (aktif); (4) komunikasi yang terjadi dua arah; (5) waktu yang digunakan dalam komunikasi lebih fleksibel dari pada terjadwal (periodisasi seperti dalam media cetak), dan (6) komunikasi berlangsung pada suatu tempat yang 'diciptakan' oleh para consumer (Rogers, 1998).

\section{METODOLOGI}

Penelitian menggunakan paradigma interpretif konstruktivis dengan metode reception analysis, di mana secara metodologis reception analysis adalah merujuk pada sebuah komparasi antara analisis tekstual wacana media dan wacana khalayak, yang hasil interpretasinya merujuk pada konteks, seperti cultural setting dan context atas isi media lain (Jensen, 2003 : 139). Khalayak dilihat sebagai bagian dari interpretive communitive yang selalu aktif dalam mempersepsi pesan dan memproduksi makna, tidak hanya sekedar menjadi individu pasif yang hanya menerima saja makna yang diproduksi oleh media massa (McQuail, 1997:19).

Studi reception analysis berusaha untuk mengetahui bagaimana khalayak memahami, menginterpretasi isi pesan (memproduksi makna), berdasarkan pengalaman (story of life) dan pandangannya selama melakukan interaksi dan mengonsumsi isi media online selama ini. Konstruksi pemahaman informan atas isi media yang terintegrasi dalam kehidupan kesehariannya merupakan sebuah proses panjang yang mengakumulasi menjadi sebuah pengalaman yang sangat berharga dalam diri informan, termasuk pemahaman mereka akan interaktivitas. Peneliti meletakkan kebenaran-kebenaran atau asumsi-asumsi alamiah atas fenomena (bracketing) yang dipahami oleh pengakses atas wacana media online dan interaktivitas. Kemudian dengan wawancara, peneliti mendapatkan pengakuan dan pengalaman-pengalaman sehari-hari mereka selama menjadi pengakses situs Suara Surabaya.net.

Sasaran penelitian adalah media Suara Surabaya.net, informan adalah users yang mengakses situs Suara Surabaya.net sekaligus sebagai pengakses, ditentukan secara purposif dengan kriteria orangorang (pengakses/ users) yang log on mengakses situs www.suarasurabaya.net online dan mempunyai kontak dengan Suara Surabaya melalui mekanisme feedback online serta berdasarkan database yang dimiliki media tersebut. Baik sebagai existing netter maupun yang masuk dalam target market. Informan berjumlah 14 orang (laki-laki semua); umur antara 33-56; pendidikan SMA, diploma, dan universitas; tinggal di Sidoarjo, Surabaya, Gresik, Sydney, Malden (Massachusset US), Glasgow (Inggris), Riau, dan Samarinda; etnik Toraja, Jawa, dan Cina; pekerjaan dosen, direktur perusahaan, manajer, konsultan arsitektur, dan teknisi. Memiliki intensitas yang berbeda dalam mengakses situs Suara Surabaya. net, di mana terdapat informan yang setiap hari mengakses Suara Srabaya.net (satu kali sehari, \pm 30 menit); sering (duatiga kali seminggu, atau satu bulan enam kali); jarang (satu bulan sekali); pernah (tergantung kebutuhan).

Teknik pengumpulan data primer melalui wawancara mendalam (indepthinterview) tatap muka 10 orang, dan dua orang lewat telepon, bertempat di kantor dan di rumah, termasuk wawancara secara tertulis dua orang menggunakan sarana e-mail bagi yang berdomisili di luar negeri. Dokumen-dokumen yang digunakan dalam penelitian ini 
berupa database pengakses/ surfer yang diperoleh dari redaksi Suara Surabaya. net. Hasil wawancara mendalam (indepth interview) diinterpretasi secara kualitatif untuk menjawab permasalahan penelitian. Triangulasi (triangulation) data dilakukan untuk keabsahan data dengan membandingkan data yang diperoleh dari pengakuan informan tentang data yang sama, untuk mencari makna dibalik data. Tinjauan pustaka yang berisikan konseptual teoritik termasuk review literature digunakan sebagai panduan dalam menganalisis hasil temuan data. Peneliti memberikan kesempatan yang terbuka kepada informan untuk menentukan batasan-batasan konsep yang dipakai dalam menginterpretasi makna yang kemudian dianalisis secara konseptual teoritik.

\section{TEMUAN}

Peneliti kualitatif berusaha memberikan makna-makna atas data yang diperoleh, menterjemahkannya, dan membuat data bisa dipahami. Peneliti masuk sebagai orang luar untuk melihat apa yang sesungguhnya terjadi, serta berusaha menemukan esensi atau sense of meaning dalam data tersebut dari sudut pandang orang yang melakukan studi atau second-order-interpretation (Neuman, 2006: 166).

\section{Teknologi Memberikan Kekuatan Brand Bonding Suara Surabaya (SS)}

Hasil wawancara dengan pengelola media online Suara Surabaya. net menyatakan bahwa mereka mengembangkan radio internet dan jurnalistik online sekaligus karena tuntutan perkembangan. Media harus tetap dekat kepada audience nya dimana pun mereka berada. Informasi audio dan video dapat disimpan dalam bentuk digital dan memudahkan pendengar untuk menelusurnya kembali (archive file). Radio sudah tidak bisa dibatasi jangkauannya secara geografis dan frekuensi. Radio harus go online dengan teknologi internet, agar kecanggihan editorial mampu memberdayakan pendengarnya mengakses berita lokal yang mereka pilih. Juga menambah value added dan kekuatan brand bonding (station loyality) pada pendengar Suara Surabaya (SS) di manapun mereka berada. Akhirnya SS bukan sekedar radio tetapi telah menjadi komunitas yang memonitor persoalan kehidupan keseharian warga kota Surabaya dan sekitarnya yang masuk ke ruang publik (publicsphere).

Informan merasakan bahwa rutinitas mengakses Suara Surabaya.net (SS.net) yang dilakukannya karena memang membutuhkan informasi mengenai Surabaya dan mempunyai ekspektasi informasi terbaru (aktual) yang tidak bisa diperoleh dari media lain. Sementara itu, informan yang berdomisili di luar negeri karena pengalaman masa lalu selama tinggal diSurabaya, sangathafalmengenai kondisi Surabaya dan sekitarnya, baik dari sisi jalan, kesemrawutan atau hiruk pikuk Kota Surabaya, suasana panasnya Kota Surabaya, dan sebagainya. Artinya, terdapat unsur nostalgia dan ikatan emosional (identitas orang Surabaya), membandingkan masa lalu dengan kondisi saat ini, sekaligus ketika mereka menelusuri setiap hyperlink yang terdapat di website SS.net merupakan hiburan tersendiri. Perilaku media habit mengakses SS.net umumnya dilakukan pada malam hari, bahkan sampai tengah malam. Berita bisa langsung diakses, bahkan users bisa ikut memberikan masukan-masukannya melalui e-mail ke redaksi SS.net. 


\section{Radio Online Memberikan The Sense of Excitement}

Teks situs SS.net menurut para informan (as netter atau users) sangat menarik dan memberikan semacam user experience melalui browsing dengan layar dan user interface yang menawarkan pengalaman menyenangkan. SS.net menawarkan interaktivitas yang diperoleh lewat hyperlinks dan mekanisme feedback (Critiques, Comments, Question) yang melibatkan users. Users bisa membuka komunikasi dengan redaksi. Di samping itu, dengan mendengarkan radio online memberikan the sense of excitement karena bisa melihat dan mengenal dekat dengan penyiar. Teknologi live streaming memungkinkan penyiar yang ada di dalam studio untuk mendengar dan melihat dengan pengaksesnya.

Peristiwa Lumpur Lapindo di Sidoarjo menjadi "peristiwa yang hidup", mampu memberi drama, karena narasinya cukup kuat dengan konteks situasi sangat dramatis dalam gaya bertutur dalam menghayati peristiwanya. Relasi radio yang imajiner berubah menjadi visual (intertextuality) atau dari imajinasi menjadi impresi. Mitos tentang radio yang hanya bisa didengarkan lewat telinga saja berubah bentuk menjadi radio yang audio visual, dimana newsroom bisa dilihat oleh pengakses. Radio on online seperti kata Castells mampu membangun realitas kemayaan yang nyata, real virtuality. Suara Surabaya memiliki video streaming yang memungkinkan pengakses internet melihat kondisi studio Suara Surabaya.

Konvergensi media penyiaran dengan internet menciptakan global audience. Konvergensi dipahami users sebagai kemudahan mendapat informasi tanpa harus berada di satu tempat tertentu. Di mana pun dan kapan pun mereka berada bisa mendapatkan informasi terbaru. Ada kemudahan mengakses berita-berita terkini secara realtime (seketika) dengan video streaming secara mobile. Oleh karena itu, bagi informan yang sering bepergian karena pekerjaan, tetapi keluarga tetap domisili di Surabaya, mereka merasa dimudahkan dengan adanya SS.net. Walaupun mereka berada di luar kota Surabaya, users tetap bisa mengikuti perkembangan informasi seputar situasi dan kondisi Surabaya melalui hyperlink Rubrik Berita Terkini dan Kelana Kota di SS.net.

Rubrik Berita Terkini menjadi pilihan informan untuk selalu diakses karena peristiwa atau isu-isu mutakhir menyangkut berita peristiwa politik, ekonomi bisnis, olahraga sampai teknologi diberitakan, baik secara nasional maupun internasional. Sehingga sesama users ketika berinteraksi dalam situs ini memandang 'halaman' berita terkini mampu memenuhi kognisi pengetahuan yang aktual dengan murah, mudah dan cepat. Kesadaran intersubjektif tersebut bertemu dalam ruang sosial maya, lantas membentuk stock of knowledge terhadap keberadaan Radio SS. Ditambah lagi, penetrasi media cetak harian pagi sampai ke daerah diterima sore hari, seperti yang dirasakan salah satu informan yang berdomisili di Duri, Riau. Informan ini sangat jarang membaca surat kabar cetak, karena surat kabar pagi datang sore hari.

Informan yang bekerja mendapat dukungan fasilitas perusahaan untuk para pegawainya dengan free access internet, sehingga fleksibilitas dan kemudahan akses ke SS.net tidak ada kendala. Di sampingitu, menurut informan mengikuti berita televisi dipandang tidak fleksibel, karena waktu tayang sering tidak pas dengan jam mereka bekerja. Artinya 
televisi masih menggunakan periodisasi waktu jam tayang pemberitaan. Sedangkan media online sewaktu-waktu bisa diakses untuk mendapatkan berita terbaru yang belum ada di surat kabar. Sehingga ini menjadi temuan menarik. Terdapat kecenderungan media habit informan yang bergeser. Informan lebih banyak mengecek e-mail dan membaca berita-berita terbaru dari SS.net karena membutuhkan informasi yang cepat, mudah, dan singkat pada pagi hari dan menjelang pulang kantor sore, untuk mengantisipasi kondisi kemacetan jalan sebelum pulang kantor.

Sedangkan Rubrik Kelana Kota menjadi pilihan informan untuk diakses karena rubrik ini merupakan core program Suara Surabaya, yang juga didokumentasikan dalam bentuk WebNews, berisi muatan lokal, nasional dan internasional yang mempunyai dampak terhadap ekonomi, sosial, dan politik di Surabaya dan Jawa Timur. Mereka memilih rubrik tersebut, karena isu lokalitas berita (Surabaya dan Jatim) sangat menonjol dalam pemberitaannya, dibandingkan dengan media online lainnya. Apalagi disertai gambar (foto), suara (radio online dan audio on demand) dan video (video on demand), sehingga lokalitas berita mampu memberikan feel sense of belonging karena sense of shared identity and values adanya unsur 'kedekatan' lingkungan akan kampung halaman, sehingga menjadi daya tarik utama mereka untuk mengaksesnya walaupun mereka berada di luar Surabaya..

Sementara bagi informan yang pernah tinggal di luar negeri (Glasgow, Inggris) karena tugas belajar mengaku jauh dari sanak keluarga tentunya sangat merindukan berita tentang tanah air. Mendengarkan Radio Online SS bisa diakses dari komputer, gadget mobile phone (suarasurabaya.net/ mobile) sangat mengasyikan, seperti layaknya mengemudi mobil di jalanan kota Surabaya sambil mendengarkan liputan lalu lintas Surabaya. Walaupun realitanya ia berada ribuan kilometer dari Surabaya, tetapi Radio Online SS bisa 'mendekatkan' pendengarnya secara maya (brand bonding) sehingga bisa mengobati kerinduan Surabaya dan keluarga. Umumnya kebiasaan mengakses SS.net dilakukan informan pada malam hari, waktu luang atau di kantor

Sedangkan menurut informan yang telah menetap di Sydney, Australia, sejak 2002 dan satu orang menetap di Massachusetts, USA sejak 2001 mengatakan bahwa, mengakses SS.net mampu memberikan kesan dan pengalaman tersendiri saat mana mereka sudah domisili di luar negeri tetapi seperti berada di Surabaya. Di samping itu bila mendengarkan radio online, kedua informan yang lahir di Surabaya ini merasakan "Surabaya jauh di mata tetapi tetap dekat di hati, di telinga dan di tangan (karena memegang mouse)". Makna pernyataan tersebut adalah mengakses SS.net karena adanya ikatan emosional terhadap asal-usul dan keluarga, sehingga mereka tetap mengikuti pemberitaan tentang situasi dan kondisi Surabaya. Media SS.net mereka pandang lebih 'dekat' dibanding media online lainnya, karena mampu memenuhi harapan mendapatkan informasi tentang Surabaya dan sekitarnya. Rubrik Kelana Kota yang merupakan core program Suara Surabaya, yang juga didokumentasikan dalam bentuk WebNews, berisi muatan berita local, nasional dan internasional menyangkut ekonomi, politik dan sosial di Surabaya dan Jawa Timur menjadi 
menu rutin untuk diakses.

Interaktivitas media SS.net menurut peneliti memberikan users eksplorasi realitas untuk mengetahui dan mengikuti berita 'secara langsung' Kota Surabaya, tanpa harus menunggu sampai besok. Di samping itu, informan merasakan impresi tersendiri mendengarkan secara live radio online hari itu, termasuk komentarkomentar dari pendengar, bukan berita yang diedit oleh media tersebut. Informan sesekali melakukan diskusi online dengan pengelola dan pengakses lain di website SS.net untuk topik-topik yang menarik perhatian seputar sosial, ekonomi, dan bisnis. Menurut informan yang mempunyai latarbelakang wiraswasta, rubrik ini wajib diikuti. Rubrik ini mengetengahkan isu-isu bisnis wajib mereka ikuti dengan baik untuk mendapatkan referensi pengetahuan terkini tentang situasi bisnis di Surabaya dan Indonesia. Rubrik Ekonomi Bisnis merupakan hasil reportase dan ulasan para reporter SS.net yang menyangkut pemberitaan kebijakan-kebijakan seputar ekonomi bisnis. Informan merasakan apa yang diberitakan dalam rubrik ini masih kurang mendalam dalam ulasannya (analisis bisnis). Sehingga kesannya pemberitaan seputar kegiatan ekonomi di Surabaya saja yang diberitakan. Untuk topik ekonomi secara nasional informan mengakses website lain, yang jauh lebih mendalam ulasannya.

Di sisi lain seperti diakui oleh informan yang praktisi IT, ternyata jauh lebih mudah mengakses internet karena tersedia di kantor dan di rumah, dari pada mengakses media lain. Sehingga akhirnya segala informasi yang diperolehnya lewat internet. Ia mencontohkan, akan sangat susah menghubungi nya lewat telepon, tetapi dengan sarana e-mail atau yahoo messenger (software yang bisa digunakan untuk melakukan obrolan di internet) justru lebih cepat direspon. Hal ini karena konteks pekerjaan yang mengharuskan ia berada di depan komputer dan tidak terbatas jam penggunaannya, sehingga berdasarkan pengalamannya sebagai heavy users, ia mempunyai kebiasaan untuk membookmark situs-situs favorite (bagus) yang menjadi langganannya untuk dikunjungi secara rutin, salah satunya situs SS.net.

\section{Radio Online Sebuah Inovasi Cerdas}

Berdasarkan pengakuan para informan ditemukan bahwa, teknologi komunikasi mampu menjadikan sesuatu yang lokal menjadi sesuatu yang mengglobal. Juga memberikan pendengar impresi yang mendalam ketika akses radio online untuk melengkapi sumber informasinya. Oleh karena itu, Radio konvensional (berdasarkan frekuensi) di abad internet dituntut untuk bisa melakukan pemberdayaan (empowerment) pendengar atau membuat inovasi untuk pendengarnya agar cerdas. Pendengar sedang berubah ke interaktif media dan cenderung mobile untuk memperoleh informasi yang cepat, netral dan fleksibel. Pengakses berada di mana-mana dan sifatnya global, tidak bisa dibatasi lagi oleh dimensi geografis, ruang, dan waktu. Manusia modern di abad internet tidak saja hidup di perkampungan global (global village), tetapi menjadi bagian dari khalayak global yang mampu memproduksi materi lokal (karakteristik pull dalam media online) untuk disebarkan secara global. Khalayak menjadi lintas negara.

Editorial issues dalam radio newsroom menjadi kekuatan yang menarik pendengar dimana pun. Teknologi konvergensi multimedia dan internet menyebabkan percepatan diseminasi 
arus informasi. Media tidak terpaku lagi dengan periodisasi waktu terbit, siaran yang terbatas jangkauannya dan khalayak yang terbatas berada di tempat tertentu. Tetapi di sisi lain, diperoleh kenyataan bahwa di Indonesia regulasi penyiaran (broadcast) menggunakan internet masih terkesan dibiarkan bebas. Sehingga memungkinkan siapa saja (pribadi, kelompok/komunitas, perusahaan, instansi) menciptakan website atau media konvensional mengembangkan spektrum 'pancaran' siarannya dengan teknologi internet secara bebas.

\section{SIMPULAN : Karakter Imajinasi Menjadi Impresi}

Berdasarkan uraian dan penjelasan yang telah dikemukakan maka dapat disimpulkan bahwa pemahaman dan pemaknaan pengakses (users) terhadap pengalaman-pengalaman mengakses Suara Surabaya.net (SS.net) sangat menarik karena mampu memberikan user experience melalui browsing dengan layar dan user interface yang menawarkan pengalaman menyenangkan. SS.net menawarkan interaktivitas yang diperoleh lewat hyperlinks dan mekanisme feedback (Critiques, Comments, Question) yang melibatkan users. Users bisa membuka komunikasi dengan redaksi. Disamping itu, mendengarkan radio online memberikan the sense of excitement karena bisa melihat dan kenal dekat dengan penyiar. Relasi teks radio yang imajiner berubah menjadi visual (intertextuality) atau dari imajinasi menjadi impresi. Mitos tentang radio yang hanya bisa didengarkan lewat kuping bergeser dan berubah bentuk menjadi audio visual yang cepat, murah dan seketika.

Media online SS.net sebagai portal news yang menyajikan berita lokal Surabaya, Jawa Timur dan Nasional disajikan dengan dokumen audio dari sumber berita terpercaya (cepat dan murah) membantu melengkapi khalayak dalam memenuhi informasi dengan cepat dan detail. SS.net telah menjadi konektor antara users dengan komunitasnya dan berusaha membangun mindset perilaku warga yang kritis, peduli pada kotanya dengan membangun kultur terbuka multiarah dicintai oleh wargakota sebagai stakeholders. Konvergensi media penyiaran dengan internet menciptakan global audience. Konvergensi dipahami sebagai kemudahan mendapat informasi tanpa harus berada di satu tempat tertentu. Dimana pun dan kapan pun mereka berada bisa mendapatkan informasi terbaru. Ada kemudahan mengakses berita-berita terkini secara realtime (seketika) dengan video streaming. Teknologi komunikasi internet dalam radio mampu menjadikan lokalitas menjadi sesuatu yang mengglobal. Juga memberikan pendengar mengakses radio virtual mereka untuk melengkapi sumber informasinya. Berikut adalah gambar tampilan depan Radio Suara Surabaya.

\section{DAFTAR PUSTAKA}

Alasuutari, Pertti. (ed).(1999). Rethinking the Media Audience. London:Sage

Baran, Stanley J. (2003). Mass Communication Theory; Foundations, Ferment, and Future, $3^{\text {rd }}$ edition. Belmon, CA : Thomson

Bungin, Burhan; New Media dan Perkembangannya; Konstruksi Sosial Telematika dan Inovasi Media Baru, Seminar dan Lokakarya "Being Local in National Context : Understanding Local Media and Its Struggle", Universitas Kristen Petra, di Surabaya 14 Oktober 2002.

Crissel, Andrew and Starkey,Guy. (1998). News on Local Radio; Local Journalism 
and Local Media, Making the Local News. Edited by Bob Franklin. New York: Routledge.

Dewdney, Andrew., and Ride, Peter. (2006). The New Media Handbook. London: Routledge.

Dijk, Jan Van. (2006). The Network Society; Social Aspects of New Media. $2^{\text {nd }}$ edition. London: SAGE Publications Ltd.

------, Jan Van. (2004). The SAGE Handbook of Media Studies. Editor-in-Chief, John D.H. Downing. Associate Editors; Dennis McQuail, Philip Schlesinger, Ellen Wartella. California : SAGE

Effendy, Onong Uchjana. (2005). Komunikasi dan Modernisasi, Bandung: Mandar Maju

Fidler, Roger. (1997). Mediamorphosis, Understanding New Media. Pine Forge Press, Thousand Oaks (calif), .

Ibrahim, Idi Subandi. (2004). Sirnanya Komunikasi Empatik; Krisis Budaya Komunikasi dalam Masyarakat Kontemporer: Bandung: Pustaka Bani Quraisy.

Jensen, Jens Frederik. (1998). Communication Research after The Mediasaurus? Digital Convergence, Digital Divergence. The Media Lanscape in Transition. Research on New Information Technology. In Nordicom Review 1/98. Nordicom, Goterborgs Universitet.

Jensen, Klaus Bruhn. 2003. A Handbook of Qualitative Methodologies for Mass Communication Research. London : Routledge

-------, Klaus Bruhn. 2002. A Handbook of Media and Communication Research, Qualitative and Quantitative Methodologies. London : Routledge

Kung, Lucy (2008). Strategic Management in The Media; Theory to Practice. London: SAGE

Lister, Martin. (2003). New Media : A Critical Introduction. London: Routledge
Livingstone, Sonia (2003). The Changing Nature of Audiences, from the Mass Audience to Interactive Media User. A Companion to Media Studies, Edited by Angharad N. Valdivia. Malden: Blackwell Publishing.

Lorimer, Rowland. 1994. Mass Communications : A Comparative Introduction. Manchester, UK: Manchester University Press

Masduki. (2003). Radio Siaran dan Demokratisasi. Yogyakarta : Jendela

Muljono; Sistem Berita Elektronika di Intranet Universitas Pelita Harapan Menggunakan Lotus Notes dan Domino, Jurnal Ilmiah Universitas Pelita Harapan, LPPM-UPH Menara UPH - Lippo Karawaci - Tangerang. Vol. 4/No.7 Agustus 2001, Hal. 37.

McLuhan, Marshall. (1999). Understanding Media; The Extension of Man. London: Routledge.

McQuail's, Denis. (2010). McQuail's Mass Communication Theory. $6^{\text {th }}$ edition. London: SAGE Publications, Inc.

--------, Denis. (2001). Mass Communication Theory. London. $4^{\text {th }}$ edition: SAGE Publications, Inc.

McQuail, Denis. 1997. Audience Analysis. London. SAGE Publications, Inc.

Nellis, Kelly Berg. (2004). Technology and Social Change: The Interactive Media Environment, Dalam Balwin, John R; Perry, Stephenn \& Moffit, Marry Anne. Communication Theories for Everyday Life. Boston: Pearson Education, Inc.

Neuman, W. Lawrence. 2006. Social Research Methods: Qualitative and Quantitative Approaches. Needham Height MA : Allyn \& Bacon.

Oetama, Jacob. (2001). Pers Indonesia Berkomunikasi dalam Masyarakat Tidak Tulus: Percetakan PT. Gramedia. Jakarta, Oktober.

Online News Association [ONA], Digital Journalism Credibility Study, 
http://www.journalists.org/Programs/ Study.htm, diakses 7 Pebruari 2002.

Pavlik, John V and Shawn McIntosh. (2004). Converging Media, An Introduction to Mass Communication. Boston : Pearson Education, Inc.

Pavlik, John V. (2001). Journalism and New Media: Columbia University Press

Pavlik, John V. (1998). "The Future of On-Line Journalism," chapter in Wickham, Kathleen, On-Line Journalism Perspective (CourseWise Publishing, Inc.).

Perebinossoff, Philippe. (2005). Programming for TV, Radio and The Internet, Strategi, Development and Evaluation. Second Edition : Focal Press. Elsevier Inc

Rahmat, Jalaludin. (2002). Metode Penelitian Komunikasi. Bandung : PT.Remaja Rosdakarya.

Runtiko, Agus Ganjar. 2008. Konvergensi Media dan Perpindahan Ruang Publik (Reaktualisasi Pemikiran Habermas), dalam Jurnal Observasi, Vol.6, No. 2, 2008. Bandung: Simbiosa Rekatama Media

Salim, Peter dan Yenny Salim. (1991). Kamus Bahasa Indonesia Kontemporer. Jakarta: Modern English Press.

Scanlan, Christopher; The Web and The Future of Writing, Poynter Reporting and Writing Group Leader, http:// www.poynter.org/centerpiece/062100. $\underline{\mathrm{htm}}$, diakses Juli 2002

Stovall, James Glen. (2004). Web Journalism of a New Medium. University of Alabama: Pearson Education Inc.

Supelli, Karlina (2010). Ruang Publik Dunia Maya; dalam Ruang Publik, Melacak "Partisipasi Demokratis" dari Polis sampai Cyberspace. Editor: F. Budi Hardiman. Yogyakarta: Kanisius.

Straubhaar, Joseph dan Robert La Rose. (2002). Media Now: Communication Media in the Information Age: Australia: Wadsworth

Street, John. 2001. Mass Media, Politics and Society. New York: Palgrave

Severin, Werner J and James W. Tankard. (2001). Communication Theories; Origin, Methods, and Uses in the Mass Media. Fifth Edition. University of Texas at Austin: Addison Wesley Longman Inc.

Yudhapramesti, Pandan. (2009). Eksistensi Radio Siaran di Era Multimedia. Dalam Jurnal Komunikasi dan Informasi, Volume 8, No 1, April 2009: hlm.193208. Bandung: Divisi Penelitian, Pengabdian dan Penerbitan Fakultas Ilmu Komunikasi, Unpad. 